\title{
Avaliação dos resíduos de construção e demolição no dimensionamento de camada reforço de pavimentos flexíveis
}

A produção global de resíduos de construção e demolição tem aumentado significativamente ao longo das décadas recentes, causando problemas ambientais devido à sua disposição irregular. O uso de materiais reciclados então tem aumentado neste período, principalmente visando o desenvolvimento sustentável e a proteção do meio ambiente. Ao mesmo tempo, a indústria de pavimentação está sendo afetada com a diminuição da disponibilidade de recursos naturais e têmse buscado uma alternativa para substituição desses. Diante deste contexto, o presente artigo avalia a utilização de resíduos de construção e demolição (RCD) como agregados de misturas asfálticas no dimensionamento da camada de reforço de pavimentos flexíveis. Neste estudo foram utilizados resíduos provindos de obras da Universidade Federal de Juiz de Fora (UFJF) que foram empregados como agregados em misturas asfálticas do tipo pré-misturado à frio (PMF). Os materiais foram inicialmente caracterizados e as misturas asfálticas produzidas com os agregados de RCD foram avaliadas mecanicamente, por meio de ensaios de resistência, rigidez e fadiga. Posteriormente, as propriedades das misturas produzidas juntamente com dados de retroanálise do pavimento do anel viário da UFJF foram inseridos em um software de dimensionamento de pavimentos flexíveis (MeDiNa) e comparadas com uma mistura com agregados naturais, afim de se analisar a possibilidade de tais materiais como camada de reforço do pavimento. Baseado nos resultados, os agregados reciclados utilizados na pesquisa por meio de misturas à frio apresentaram qualidades de caracterização e mecânicas satisfatórias. Duas das misturas estudadas apresentaram aplicabilidade como possíve camada de reforço do pavimento flexível do anel viário da UJFJ, mostrando-se uma boa alternativa em relação a misturas quentes e com agregados naturais, uma vez que apresentam potencial econômico e ecológico.

\section{Evaluation of construction and demolition waste in the design of the reinforcement layer for flexible pavements}

\begin{abstract}
The global production of construction and demolition waste has increased significantly over the past few decades, causing environmental problems due to its irregular disposition. The use of recycled materials has therefore increased in this period, mainly aiming at sustainable development and protection of the environment. At the same time, the paving industry is being affected by the decrease in the availability of natural resources and an alternative is being sought to replace these. In this context, this article assesses the use of construction and demolition waste (RCD) as aggregates of asphalt mixtures in the design of the reinforcement layer for flexible pavements. In this study, residues from works of the Federal University of Juiz de Fora (UFJF) were used, which were used as aggregates in asphalt mixtures of the cold pre-mixed type (PMF). The materials were initially characterized and the asphalt mixtures produced with the RCD aggregates were evaluated mechanically, through resistance, stiffness and fatigue tests. Subsequently, the properties of the mixtures produced together with UFJF's ring-road pavement retroanalysis data were inserted in a flexible pavement sizing software (MeDiNa) and compared with a mixture with natural aggregates, in order to analyze the possibility of such materials as a floor reinforcement layer. Based on the results, the recycled aggregates used in the research by means of cold mixtures showed satisfactory characterization and mechanical qualities. Two of the studied mixtures showed applicability as a possible reinforcement layer for the flexible pavement of the UJFJ ring road, showing a good alternative in relation to hot mixtures and with natural aggregates, since they have economic and ecological potential.
\end{abstract}

Keywords: Construction and demolition waste; Recycled aggregates; Pavements; Sustainability; Pavement mechanics.

Topic: Engenharia Ambiental

Reviewed anonymously in the process of blind peer.
Received: 02/02/2021

Approved: 25/02/2021
Marcos Lamha Rocha (D)

Universidade Federal de Juiz de Fora, Brasil http://lattes.cnpq.br/0684505688946214 http://orcid.org/0000-0002-0581-9176

marcosIr94@gmail.com

Geraldo Luciano de Oliveira Marques (iD Universidade Federal de Juiz de Fora, Brasil http://lattes.cnpq.br/4503245454189660 http://orcid.org/0000-0003-1347-2624 geraldo.marques@ufjf.edu.br

Thaís Mayra de Oliveira (it)

Universidade Federal de Juiz de Fora, Brasil http://lattes.cnpq.br/9211120062798671

http://orcid.org/0000-0002-2838-6182

thais.mayra@ufjf.edu.br

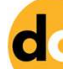

DOI: 10.6008/CBPC2179-6858.2021.002.0033

\section{Referencing this:}

ROCHA, M. L.; MARQUES, G. L. O.; OLIVEIRA, T. M.. Avaliação dos resíduos de construção e demolição no dimensionamento de camada reforço de pavimentos flexíveis. Revista Ibero Americana de Ciências Ambientais, v.12, n.2, p.377-393, 2021. DOI:

http://doi.org/10.6008/CBPC2179-6858.2021.002.0033 


\section{INTRODUÇÃO}

A gestão de resíduos é um problema ambiental, social e econômico, sendo que o aumento do consumo e o desenvolvimento das atividades econômicas continuam gerando grandes quantidades de resíduos que exigem maior esforço para reduzir e reciclar. No passado, os resíduos eram considerados descartáveis e eram eliminados em aterros sanitários. Entretanto, as tendências atuais dos sistemas de gestão de resíduos para substituir a remoção por reciclagem e a valorização refletem o potencial dos resíduos como um recurso e não como um problema (DEL REY et al., 2016).

A indústria da construção civil em áreas urbanas é um setor adequado para incentivar a utilização racional de resíduos e subprodutos industriais. Essa indústria consome grandes quantidades de matéria prima e gera enormes quantidades de resíduos durante a construção e demolição de edifícios, estradas, calçadas, pontes, etc. Estes resíduos consistem principalmente de blocos de concreto, argamassa, tijolos, concreto armado, fresagem de concreto asfáltico, assim como cerâmica, gesso e madeira (OSSA et al., 2016).

O destino dos resíduos de construção e demolição (RCD) é geralmente em aterros sanitários ou locais de resíduos inertes que não são licenciados, o que causa um grande impacto econômico e ecológico. Diante disso, surgiu-se a necessidade de procurar alternativas para gerir adequadamente os resíduos de construção e demolição, com redução, reutilização e a reciclagem. Para determinar a melhor alternativa para a eliminação destes resíduos, diferentes fatores devem ser considerados, entre os quais se incluem os tipos de materiais que podem ser reciclados, os custos da gestão de resíduos, os riscos envolvidos na reciclagem e a disponibilidade de mercados para os produtos de reciclagem (ESPARZA et al., 2020).

A ampla aplicação de concretos asfálticos e pavimentos de concreto torna possível o consumo de uma vasta quantidade de RCD. Os agregados naturais utilizados para preparar as misturas asfálticas podem ser totalmente ou parcialmente substituídos por agregados reciclados. Para além dos méritos ambientais, é também uma abordagem econômica, uma vez que a aplicação de RCD reduz o custo do material na construção do pavimento (ZOU et al., 2019).

O presente artigo tem por objetivo avaliar a viabilidade da utilização de resíduos de construção e demolição (RCD) provindos de obras na cidade Juiz de Fora/MG como agregado em misturas asfálticas para o emprego em camada de reforço de pavimentos flexíveis. As análises foram realizadas de forma mecanística, com o emprego do novo método brasileiro de dimensionamento de pavimentos (MeDiNa) para uma futura aplicabilidade de tais resíduos em projetos de reabilitação de pavimentos asfálticos.

\section{REVISÃO TEÓRICA}

\section{Resíduos de Construção Civil (RCD)}

Segundo a Resolução do Conselho Nacional de Meio Ambiente no 307 (CONAMA, 2002):

"Resíduos da construção civil são os provenientes de construções, reformas, reparos e demolições de obras de construção civil, e os resultantes da preparação e da escavação de terrenos, tais como: tijolos, blocos cerâmicos, concreto em geral, solos, rochas, metais, resinas, colas, tintas, madeiras e compensados, forros, argamassa, gesso, telhas, pavimento asfáltico, vidros, plásticos, tubulações, fiação elétricas, dentre outros, comumente 
chamados de entulhos de obras ou metralha". (CONAMA, 2002)

A norma da ABNT 15116 (2004), em consonância com a resolução do CONAMA 307 classifica os resíduos de construção civil em 4 classes: A) resíduos reutilizáveis ou recicláveis como agregados (ex: argamassa, concreto, tijolo, bloco, placas de revestimento etc.); B) resíduos recicláveis para outras destinações (ex: plásticos, papelão, metais, vidros etc.); C) resíduos para quais não foram desenvolvidos tecnologias ou aplicações economicamente viáveis que permitam a reciclagem (ex: gesso); e D) resíduos perigosos (ex: tintas, solventes, óleos etc.).

Devido ao rápido desenvolvimento da construção civil, a grande quantidade de RCDs gerados tem se tornado uma preocupação ambiental mundial. Segundo Menegaki et al. (2018), aproximadamente 35\% de RCDs gerados ao redor do mundo são dirigidos para aterros, sem nenhum tratamento adicional. Em 2017, os Estados Unidos geraram aproximadamente 569 milhões de toneladas de RCD, enquanto que a União Europeia produziu 914 milhões de toneladas (USEPA, 2017; EUROSTAT, 2017). Na China, todos os anos mais de 1,5 bilhões de resíduos de construção e demolição são produzidos, sendo que apenas $5 \%$ desses podem ser reciclados (VERISK MAPLECROFT, 2019).

Em relação ao Brasil, a busca por reciclagem e reuso dos resíduos ainda é recente em comparação com outros países, e aplicadas na maioria das vezes de maneira incorreta. Entretanto, a geração de resíduos no país é de alto impacto ambiental e as práticas de reciclagem não acompanham a quantidade produzida. A Tabela 1 apresenta a quantidade de RCD coletada no Brasil por região em 2018.

Tabela 1: Quantidade de RCD coletados no Brasil em 2018.

\begin{tabular}{lll}
\hline Região & RCD coletado (toneladas/dia) & Índice $(\mathrm{Kg} / \mathrm{hab} / \mathrm{dia})$ \\
\hline Norte & 4.709 & 0,259 \\
Nordeste & 24.123 & 0,425 \\
Centro-Oeste & 13.255 & 0,824 \\
Sudeste & 63.679 & 0,726 \\
Sul & 16.246 & 0,546 \\
Brasil & 122.012 & 0,585 \\
\hline
\end{tabular}

Fonte: ABRELPE (2018).

Á medida que o mundo continua no seu caminho de rápida urbanização, a questão mais encontrada pelos tomadores de decisão políticas e os munícipios relaciona-se com a maneira como devem lidar com as grandes quantidades de RCD. De um ponto de vista realista, deve-se admitir que a situação atual não é globalmente satisfatória, apesar do fato de alguns países desenvolvidos terem dados grandes passos utilizando resíduos. Há ainda muitos debates de como essa grande quantidade de RCD pode ser aplicada, especialmente considerando os aspectos financeiros de tais utilizações. A Tabela 2 ilustra alguns dos vários benefícios do potencial uso de RCD reciclado.

De acordo com Levy (1997), os agregados reciclados têm uma composição que dependem fortemente de qual foi a fonte que originou o resíduo e em quais momentos estes foram obtidos para a reutilização/reciclagem. Uma vez que a construção civil é composta por diferentes componentes, é de se esperar que seus resíduos sejam conjuntos de materiais distintos.

É importante notar que os materiais provindos dos resíduos de construção e demolição são não 
homogêneos como são os materiais naturais oriundos de rochas. O agregado reciclado contém outros materiais que dificulta a substituição completa de um agregado natural de boa qualidade em estruturas, portanto, isto restringe muito suas aplicações em elementos estruturais, tais como o concreto armado (KUMAR, 2017).

Tabela 2: Vantagens e consequências da reciclagem de RCD.

\begin{tabular}{|c|c|}
\hline Vantagens & Consequências \\
\hline Preservação dos recursos naturais & Proteção dos habitats naturais para o futuro \\
\hline $\begin{array}{l}\text { Redução da utilização de matéria-prima } \\
\text { naturais }\end{array}$ & Menos utilização dos recursos em declínio da terra \\
\hline Poupar recursos financeiros & $\begin{array}{l}\text { Diminuição da energia para extração, refinação, transporte e transformação de } \\
\text { materiais virgens }\end{array}$ \\
\hline Eliminação de pilhas de resíduos & Redução da emissão de gases de efeito estufa e de poluentes do ar e da água \\
\hline Redução das despesas de despejo & Redução dos custos de transporte e despejo em aterro \\
\hline Proteção ambiental & Prevenção das alterações climáticas \\
\hline
\end{tabular}

Fonte: Gedik (2020).

\section{RCD aplicados à pavimentação}

Balbo (2007) destaca a importância de destinar um fim aos materiais reciclados, que são geralmente produzidos por escórias de edificações e estruturas de concreto, sendo que estes, muitas vezes, são utilizados erroneamente ou são simplesmente descartados de maneira irregular. A utilização então destes materiais como alternativas para pavimentação é uma forma de aplicar essa grande quantidade de resíduo como agregado, substituindo o processo de extração de novas matérias-primas. Esse tipo de material apresenta grande potencial de utilização em camadas de base e sub-base e agregados em misturas asfálticas de pavimentos.

Devido a extensa malha rodoviária brasileira, que soma 1,7 milhões de quilômetros e que $12 \%$ dessa são pavimentadas, o uso de resíduos de construção e demolição no lugar de materiais convencionais vem se tornando uma ideia interessante. $O$ aspecto a ser notado é o controle tecnológico necessário a ser empregado nesses materiais no país, uma vez que o fator dificultante da utilização de RCD é sua heterogeneidade (FERNANDES, 2004).

Muitos estudos recentes vêm abordando a utilização de RCD como agregados em camadas de pavimentos. Huang et al. (2007) reportou que a utilização de materiais reciclados em pavimentos asfálticos é uma alternativa viável. Arulrajah et al. (2014) analisaram características físicas e de resistência de materiais RCD e concluíram que os resíduos apresentaram potencial para serem utilizados como camadas de base e sub-base de pavimentos. Rezende et al. (2015) monitoraram uma rodovia experimental ao longo de oito anos submetida a ações do tráfego e clima, e concluíram que os agregados reciclados utilizados podem apresentar parâmetros com o mesmo nível dos materiais naturais tradicionalmente utilizados.

Paranavithana et al. (2006) sugeriram que a aplicação de RCD em substituição parcial à agregados virgens resulta em relativa redução de módulo de resiliência e valores de creep e que houve uma tendência na qual as propriedades volumétricas das misturas com RCD tiveram seus valores reduzidos. Mills-Beale et al. (2010) analisaram misturas asfálticas produzidas com 25\%, 35\%, 50\% e 75\% de RCD e concluíram que a alta porosidade e o comportamento absortivo do RCD resultaram não apenas na redução dos valores de 
volume dos agregados minerais (VAM) e vazios preenchidos por asfalto (VFA), mas como também no volume de vazios $(\mathrm{Vv})$ e na quantidade de ligante de projeto $(\mathrm{Pb})$.

Com o objetivo de superar essas carências volumétricas causadas pela aplicação de RCD nas misturas asfálticas, novas pesquisas vêm focando na utilização de tratamentos adicionais em misturas asfálticas visando a aplicabilidade das mesmas. Pasandin et al. (2013) estudaram a cura das misturas asfálticas à $170 \mathrm{C}$ e encontraram uma melhora na resistência à umidade da mistura. Pasandin et al. (2014) avaliaram a utilização de um revestimento com emulsão betuminosa no agregado antes da mistura e relataram um incremento na adesividade do resíduo. Hou et al. (2014) utilizaram resina de silício orgânico como efeito de ativação da mistura e chegaram numa melhor estabilidade dinâmica dos materiais. Kareem et al. (2018) aplicaram uma técnica, chamada de duplo revestimento, formado por pasta de escória de cimento e Sika Tite-BE, e perceberam um decréscimo na absorção e aumento na rigidez e resistência à umidade.

\section{Pré-Mistura á Frio (PMF)}

O pavimento pode ser entendido como uma estrutura de múltiplas camadas de espessuras finitas, construída sobre a superfície do subleito, destinado a resistir as cargas do tráfego. $O$ tipo de pavimento mais utilizado no Brasil é o do tipo flexível, onde a estrutura é formada por camadas superiores constituídas de materiais asfálticos (revestimento) com elevada deformabilidade, e camadas granulares, denominadas base, sub-base e reforço do subleito (Figura 1) (BERNUCCl et al., 2006).

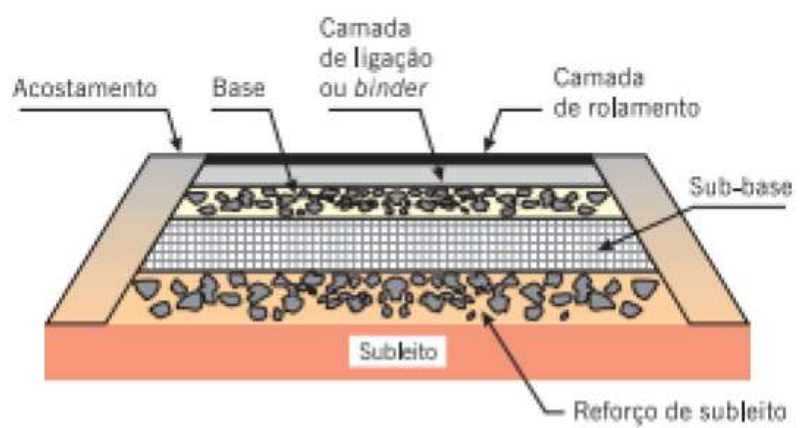

Figura 1: Seção transversal de um pavimento asfáltico. Fonte: Bernucci et al. (2006).

O revestimento asfáltico utilizado em pavimentos flexíveis é composto de uma mistura de agregados minerais e ligante asfáltico em proporções adequadas, formando uma camada resistente às ações do tráfego e do clima. As misturas usinadas podem ser do tipo à quente, onde os agregados e o ligante são misturados em altas temperaturas (conhecidas como CBUQ ou CA) ou tipo à frio, onde os materiais são combinados em menores temperaturas (SANTANA, 1993).

O tipo mais comum de misturas à frio são as misturas pré-misturadas à frio (PMF). O DNIT 153/2010 define o PMF como sendo uma mistura executada à temperatura ambiente, em usina apropriada, de agregado mineral graduado, material de enchimento (filler) e emulsão asfáltica, para espalhamento e compressão à frio. São usadas normalmente como revestimento de ruas e estradas de baixo e médio volume de tráfego ou em camadas intermediárias e em operações de manutenção e conservação.

Em obras de pavimentação, as misturas asfálticas à quente têm seu custo elevado devido ao preço 
do Cimento Asfáltico do Petróleo (CAP) e também pelo alto consumo de energia elétrica durante o processo de usinagem. Sendo assim, o PMF é uma alternativa mais econômica e sustentável, e que pode atender as qualidades técnicas exigidas para o desempenho satisfatório do pavimento. A Tabela 3 ilustra a comparação destes custos.

Tabela 3: Comparação dos custos unitários entre PMF e CBUQ (DNIT/SICRO 2 - 2015).

\begin{tabular}{lllll}
\hline Tipo de Mistura & \multicolumn{2}{l}{ Execução $\left(\mathrm{R} \$ / \mathrm{m}^{2}\right)$} & \multirow{2}{*}{ Usinagem $\left(\mathrm{R} \$ / \mathrm{m}^{2}\right)$} & Preço Total $\left(\mathrm{R} \$ / \mathrm{m}^{2}\right)$ \\
\cline { 2 - 3 } & Equipamento & Mão-de-Obra & & \\
\hline PMF & 25,54 & 7,40 & 53,89 & 104,83 \\
CBUQ & 17,45 & 5,43 & 122,88 & 175,92 \\
\hline
\end{tabular}

\section{Dimensionamento de Pavimentos Flexíveis}

O dimensionamento de um pavimento não se limita apenas a determinação das espessuras das camadas constituídas, mas como também a verificação de compatibilização dos materiais, uma vez que se trata de um sistema conjunto. No projeto para a estimativa dos materiais e espessuras alguns parâmetros são necessários, tais como: tráfego atual e esperado; clima; características do subleito; técnicas construtivas e critérios de ruptura (MEDINA et al., 2015).

No dimensionamento há dois métodos se obter as espessuras finais do pavimento: método empírico, onde se baseia por fórmulas, experiências e são restritas as condições do pavimento previamente estudados; e o método empírico-mecanístico, que se baseia em critérios de resistência, onde se utiliza de equações que preveem o desempenho estrutural do pavimento ao longo da vida útil, obtidas e aperfeiçoadas por meio de resultados de observações de campo (MELLO et al., 2016).

Diante deste contexto, desenvolveu-se no país um método mecanístico-empírico de dimensionamento de pavimentos flexíveis, denominado MeDiNa. Inicialmente, em sua tese de doutorado, Franco (2007) desenvolveu um método de dimensionamento de pavimentos asfálticos, na COPPE/UFRJ, sendo consolidado em um software computacional denominado SisPav. Em 2013, por meio de estudos da Rede de Tecnologia em Asfaltos da Petrobrás ocorreu uma pequena atualização, virando o SisPavBR, fazendo análises mais elaboradas. A partir de 2015, um Termo de Execução Descentralizada (TED) entre o IPR e o instituto Alberto Luiz Coimbra de Pós-graduação e Pesquisa de Engenharia (COPPE/UFRJ) possibilitou o surgimento de uma nova atualização do software, denominado de MeDiNa (SOUZA JÚNIOR, 2018).

O MeDiNa utiliza da rotina de Análise Elástica de Múltiplas Camadas (AEMC) que permite o cálculo de tensões e deformações sob a passagem de um eixo padrão. O programa então aplica modelo de fadiga e deformação permanente até que as espessuras ajustadas atendam aos critérios de ruptura adotadas pelo programa. Juntamente com o pacote MeDiNa e AEMC, se disponibiliza o programa BackMeDiNa, que por meio do processo de retroanálise é possível obter as características dos materiais (módulo de resiliência) em campo por meio de medidas de deflexão na pista.

\section{METODOLOGIA}

\section{Materiais}


Os materiais utilizados como agregados na pesquisa foram os resíduos de construção e demolição (RCD) oriundos de obras de demolição do Campus da Universidade Federal de Juiz de Fora (UFJF). O material foi inicialmente recolhido pela Pró-Reitoria de Infraestrutura (PROINFA) da UFJF, para posteriormente ser aplicadas as etapas de: triagem, onde se separou os agregados de materiais como tijolos, cerâmicas, vidros, etc.; e britagem, para obtenção das frações desejadas. Os materiais transformados fisicamente e mecanicamente na forma de agregado foram denominados como: Brita 1, Brita 0 e Pó de Pedra. Esses três materiais, assim como as etapas do entulho no local da demolição até a chegada ao laboratório são ilustrados na Figura 2.
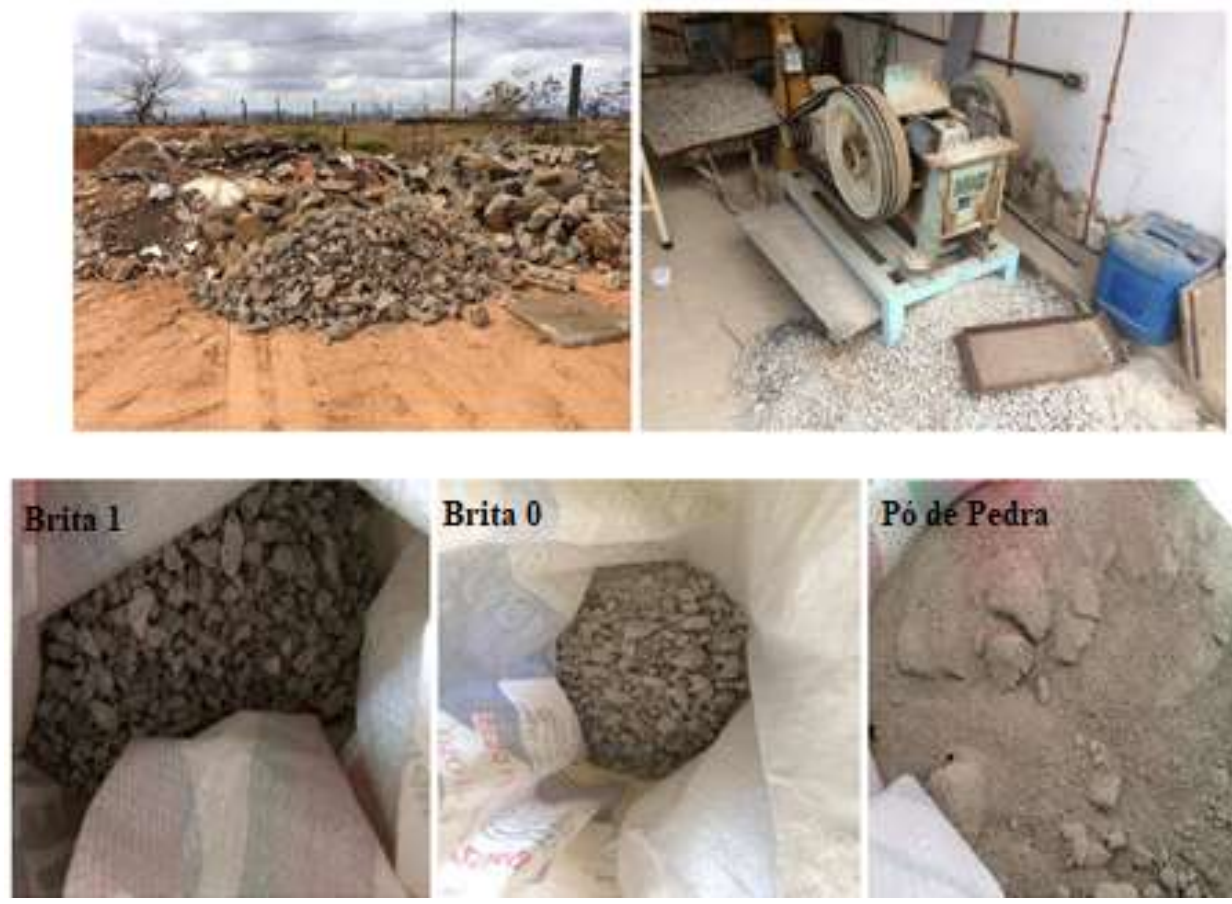

\section{Brita 0}

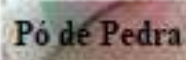

Figura 2: Etapas da produção do RCD e os resíduos coletados.

Inicialmente, com os materiais em laboratório, estes foram submetidos à ensaios de caracterização de natureza física e química, afim de se verificar sua qualidade como materiais para fins rodoviários. A Figura 3 ilustra as curvas granulométricas dos agregados utilizados, enquanto que a Tabela 4 resume os resultados dos principais ensaios de caracterização.

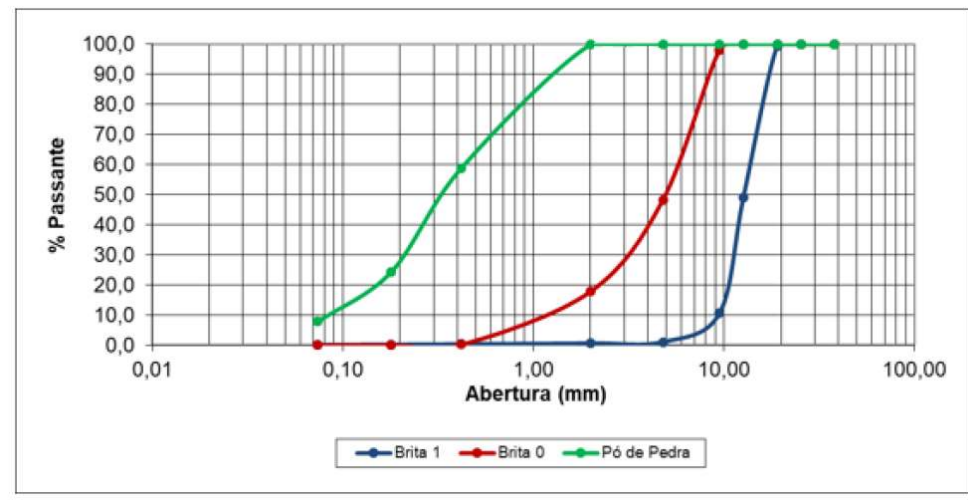

Figura 3: Curvas granulométricas dos agregados reciclados. 
Tabela 4: Características físicas e químicas dos agregados de RCD.

\begin{tabular}{llll}
\hline Ensaios & Brita 1 & Brita 0 & Pó de pedra \\
\hline Massa específica real (g/cm3) & 2,632 & 2,610 & 2,225 \\
Massa específica aparente (g/cm3) & 2,314 & 2,241 & 2,021 \\
Absorção (\%) & 4,839 & 6,276 & 7,116 \\
Índice de forma & 0,88 & 0,79 & \\
Abrasão Los Angeles (\%) & 38,8 & 44,1 & \\
Durabilidade do agregado (\%) & 5,87 & 4,91 & \\
Adesividade ao ligante (CAP 50/70) & Satisfatório & Satisfatório & \\
\hline
\end{tabular}

Para o ligante, foi utilizado a Emulsão asfáltica catiônica de ruptura lenta (tipo: RL-1C denso), fornecido pela Stratura Asfalto S/A. Os resultados dos ensaios de caracterização foram apresentados pelo fornecedor e estão ilustrados na Tabela 5.

Tabela 5: Características físicas e químicas do ligante utilizado.

\begin{tabular}{lll}
\hline Ensaios & Especificação & Resultado \\
\hline Viscosidade Saybolt Furol, 50 C (s) & 70 máx. & 25 \\
Peneiração, peso (\%) & 0,1 máx. & 0 \\
Sedimentação, 5 dias (\%) & 5 máx. & 0,5 \\
Carga da partícula & Positiva & Positiva \\
Resíduo seco & 60 mín. & 61,50 \\
pH & 6,5 máx. & 2,8 \\
\hline
\end{tabular}

\section{Métodos}

A metodologia da pesquisa compreendeu-se em 4 etapas: ensaios de caracterização física e química dos resíduos de construção e demolição; dosagem das misturas asfálticas pelo Método Marshall com duas faixas granulométricas; caracterização mecânica das misturas asfálticas com agregados de RCD; e aplicação das misturas produzidas na ferramenta MeDiNa, juntamente com dados de retroanálise, para possível aplicação como camada de reforço do anel viário da UFJF.

\section{Misturas Asfálticas}

Para o projeto de misturas asfálticas, utilizou-se duas faixas granulométricas: a Faixa $\mathrm{C}$ da norma DNIT 153-2010; e a Faixa XII de Santana (1993). No enquadramento das misturas às faixas, empregou-se a ferramenta computacional Microsoft Excel, onde variava-se as porcentagens dos três materiais, até que a granulometria final se adequasse aos limites estipulados pelas as duas faixas.

O passo seguinte foi a dosagem das misturas asfálticas para a obtenção do teor de projeto para cada faixa. Utilizou-se a norma DNER-ME 107/94 (Mistura a Frio - Ensaio Marshall), onde em um primeiro momento adotou-se cinco teores de asfalto (variados em 1\%). Entretanto, como os corpos de prova-de-prova se mostraram pouco úmidos, em uma segunda tentativa foram adotados outros três teores (variados em 2\%). Em cada corpo-de-prova (CP), foram calculados a massa específica aparente compactada (Gmb), massa específica máxima teórica (DMT), o volume de vazios (Vv), vazios dos agregados minerais (VAM) e relação betume/vazio (RBV). De acordo com os dados destes parâmetros em relação aos teores de ligante, optou-se pela escolha do teor de projeto que alcançasse os melhores resultados.

Com as misturas asfálticas e seus respectivos teores de projetos foram realizados os ensaios mecânicos de cada mistura. Para isso, foram realizados os ensaios de módulo de resiliência, resistência à 
tração por compressão diametral e ensaio de resistência à fadiga, como visto na Tabela 6.

Tabela 6: Ensaios mecânicos realizados.

\begin{tabular}{ll}
\hline Ensaios & Norma \\
\hline Módulo de Resiliência & DNIT ME 134/2010 \\
Resistência à Tração por Compressão Diametral & DNER ME 138/94 \\
Ensaio de Fadiga & DNIT 183/2018 \\
\hline
\end{tabular}

\section{Projeto da Camada de Reforço}

Visando a aplicação das misturas asfálticas à frio produzido com RCD em projetos de pavimentação, estas foram analisados como possíveis camadas de reforço do pavimento do campus da UFJF. Sua construção data da década de 1960 e, desde então, apenas uma restauração foi realizada - no ano de 1991, executandose um recapeamento com aproximadamente $5,0 \mathrm{~cm}$ de espessura.

Para a avaliação estrutural do pavimento existente, foram realizados levantamentos deflectométricos ao longo dos $2.140 \mathrm{~m}$ com o equipamento Falling Weight Deflectometer (FWD) 8833. No total, foram inventariadas 98 estações de medições das deflexões. Com os dados deflectométricos e dados de campo (espessura das camadas) realizou-se a retroanálise da estrutura do pavimento, onde por meio de um programa computacional (BackMeDiNa), obteve-se as características elásticas (módulo de resiliência) das camadas. A Figura 4 ilustra a estrutura do pavimento mediante a abertura de um poço de sondagem, assim como as espessuras das camadas.

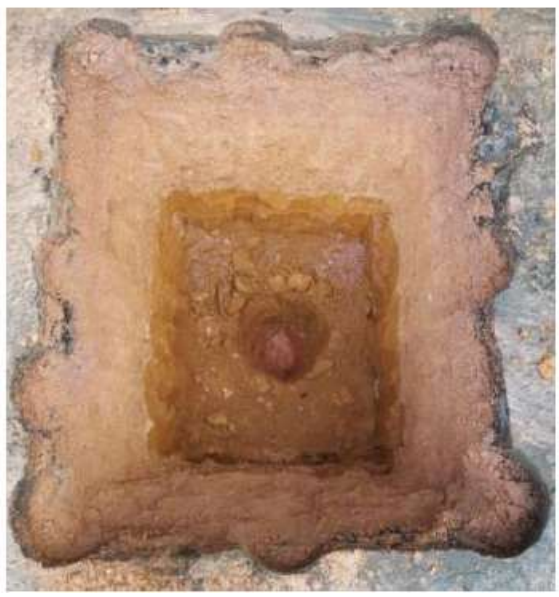

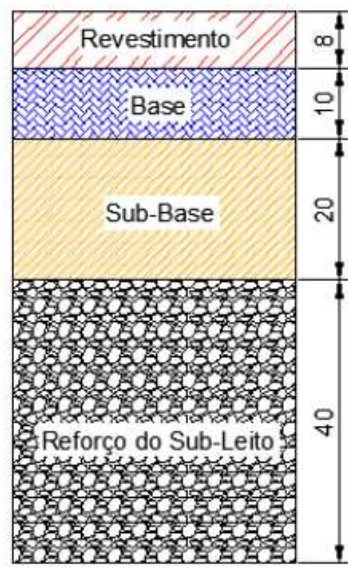

Sub-Leito

Figura 4: Poço de sondagem e espessura das camadas do pavimento. Fonte: Machado (2019).

O passo seguinte foi analisar a mistura asfáltica de RCD como possível camada de reforço no programa computacional MeDiNa. Para o dimensionamento da camada de reforço de pavimentos flexíveis é necessário que usuário entre com os dados complementares da camada asfáltica existente, sendo eles o percentual de área trincada e índice de irregularidade longitudinal. Estes foram produzidos por meio de Levantamento Visual Contínuo Informatizado ( $\mathrm{LVCl}$ ) e por meio de um perfilômetro a laser.

São necessários também dados relativos ao tráfego do trecho: tipo de via, volume médio diário (VMD), fator de veículo (FV), porcentagem de veículos na faixa de projeto, taxa de crescimento do tráfego e período de projeto em anos. O valor do VMD foi estabelecido, para o primeiro ano da análise (2020), como sendo 9.300 veículos, considerando $90 \%$ carros de passeio e $10 \%$ ônibus urbanos, e uma estimativa de 50\% 
de veículos na faixa de projeto, resultando em $\mathrm{N}$ de 6,79E+6 no período de 10 anos. Além disso, entrou-se com os dados do ensaio de módulo de resiliência da camada de reforço (de RCD).

\section{RESULTADOS}

O projeto de mistura de agregados teve como objetivo a montagem dos esqueletos minerais a fim de enquadrar as granulometrias nas faixas desejadas. A Tabela 7 descreve as porcentagens de cada material para enquadramento nas faixas escolhidas.

Tabela 7: Mistura de agregados para as duas faixas granulométricas.

\begin{tabular}{lll}
\hline Material & Faixa C & Faixa XII (Santana, 1993) \\
\hline Brita 1 & $45 \%$ & $5 \%$ \\
Brita 0 & $45 \%$ & $50 \%$ \\
Pó de Pedra & $10 \%$ & $45 \%$ \\
\hline
\end{tabular}

Uma vez agregados de RCD tendem a ter mais absorção que agregados naturais é de se esperar maiores teores de asfalto de misturas produzidas com resíduos. Diante disso, optou-se inicialmente por um teor de $10 \%$ de emulsão, e utilizou-se $\pm 2 \%$ para os demais CPs. Para cada teor, foram montados três CPs, sendo realizados ensaios volumétricos e mecânicos para obtenção do teor de projeto.

Entretanto, após as primeiras dosagens, percebeu-se nos corpos de prova uma dificuldade na mistura, pois se encontravam muito secas e com baixo teor de ligante. Então, como uma outra alternativa, resolveu-se aplicar o método Marshall novamente, mas com teores superiores aos primeiros. Foi escolhido o teor de $13 \%$ como inicial, e uma variação de $\pm 2 \%$. Além disso, foi possível analisar mecanicamente e como camada de reforço, misturas asfálticas com a mesma faixa granulométrica com diferentes teores de ligante asfáltico. A norma DNIT 153-2010 ES especifica apenas três requisitos necessários para a escolha do teor de projeto: Porcentagem de vazios (VV), estabilidade mínima (E), e fluência (f). Mediante a construção de gráficos, obtiveram-se os teores de ligante asfáltico para as misturas descritos na Tabela 8.

Tabela 8: Valores de teores de projeto para as quatro misturas asfálticas.

\begin{tabular}{lll}
\hline Mistura & Faixa & Teor de ligante \\
\hline 1 & C (DNIT 153/2010) & $9 \%$ \\
2 & XII (SANTANA, 1993) & $10 \%$ \\
3 & C (DNIT 153/2010) & $11 \%$ \\
4 & XII (SANTANA, 1993) & $11 \%$ \\
\hline
\end{tabular}
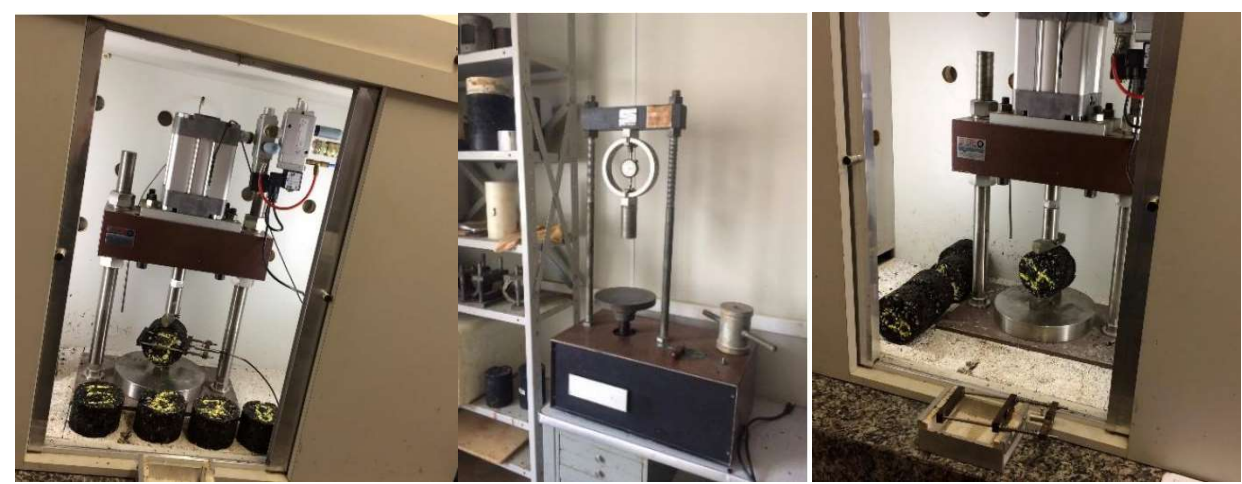

Figura 5: Ensaios mecânicos em misturas asfálticas: Módulo de Resiliência; Resistência à Tração; Resistência à Fadiga.

Com os teores de projeto definidos, para cada mistura foram moldados três corpos de prova para a 
realização do ensaio de módulo de resiliência, três para o ensaio de tração à compressão diametral e cinco para o ensaio de resistência à fadiga. A Figura 5 ilustra os equipamentos utilizados para tais ensaios.

A Tabela 9 apresenta os valores médios e de desvio padrão (DP) de módulo de resiliência e resistência à tração, assim como a razão entre ambos os valores.

Tabela 9: Resultados mecânicos das misturas asfálticas.

\begin{tabular}{llllllll}
\hline Mistura & Faixa & \% Lig. & $\begin{array}{l}\text { RT Médio } \\
\text { (MPa) }\end{array}$ & DP & $\begin{array}{l}\text { MR médio } \\
\text { (MPa) }\end{array}$ & DP & MR/RT \\
\hline Mistura 1 & C (DNIT 153/2010) & $9 \%$ & 0,52 & 0,65 & 860 & 322 & 1.653 \\
\hline Mistura 2 & XII (Santana, 1993) & $10 \%$ & 0,30 & 0,07 & 802 & 256 & 2.674 \\
\hline Mistura 3 & C (DNIT 153/2010) & $11 \%$ & 0,29 & 0,04 & 1.392 & 306 & 4.802 \\
\hline Mistura 4 & XII (Santana, 1993) & $11 \%$ & 0,25 & 0,03 & 940 & 137 & 3.761 \\
\hline
\end{tabular}

O resultado dos ensaios de vida de fadiga para as quatro misturas em forma de curvas de Wohler, assim como suas expressões obtidas por regressões lineares é exposto na Figura 6. Por meio das curvas é possível classificar as misturas asfálticas quanto à resistência à fadiga através do cálculo da área sobre a curva de fadiga em espaço log-log. Para o cálculo do fator de área de fadiga (FAF) foi utilizado um intervalo de deformação fixo entre 0,00025 e 0,002 mm/mm, visto que a grande maioria das misturas foi ensaiada nestes níveis de deformação. A Tabela 10 ilustra os valores de FAF de cada mistura, assim como os parâmetros de fadiga (k1 e n1) obtidos por regressão e que são dados de entrada no programa MeDiNa.

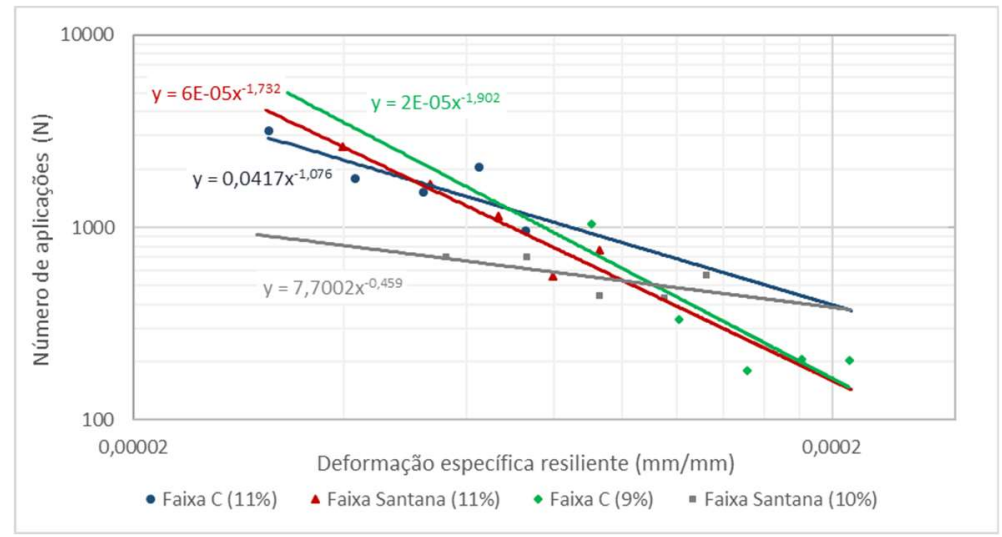

Figura 6: Curvas de Wohler.

Tabela 10: Constantes experimentais das curvas de fadiga e FAF das misturas asfálticas.

\begin{tabular}{llllll}
\hline Mistura & Faixa & \% Lig. & k1 & n1 & FAF \\
\hline Mistura 1 & C (DNIT 153/2010) & $9 \%$ & 0,0417 & $-1,076$ & 0,360 \\
\hline Mistura 2 & XII (Santana, 1993) & $10 \%$ & $6 \mathrm{E}-5$ & $-1,732$ & 0,530 \\
\hline Mistura 3 & C (DNIT 153/2010) & $11 \%$ & $2 \mathrm{E}-5$ & $-1,902$ & 0,767 \\
\hline Mistura 4 & XII (Santana, 1993) & $11 \%$ & 7,7 & $-0,459$ & 0,121 \\
\hline
\end{tabular}

Na etapa de retroanálise dos módulos de resiliência do pavimento existente no anel viário da UFJF, inicialmente o trecho foi divido em segmentos homogêneos por meio do Método das Diferenças Acumuladas, preconizada pela AASHTO (1993) e apresentado no Manual de Restauração de Pavimentos Asfálticos (DNIT, 2006). Para o cálculo, utilizou-se da deflexão máxima como parâmetro para a divisão dos segmentos, resultado em oito segmentos homogêneos.

Com a utilização do programa BackMeDiNa entrou-se com os dados deflectométricos obtidos por meio do equipamento FWD, assim como as espessuras das camadas (inspeção) e os coeficientes de Poisson 
(obtidos por meio de tabelas). O software trabalha de forma iterativa, alterando os módulos de resiliência das camadas, até que a bacia de deflexão teórica se aproxime da bacia de campo para um determinado erro aceitável. Os módulos então de cada segmento foram considerados como a média dos módulos de cada bacia pertencente ao seu segmento. A Tabela 11 resume os valores médios dos módulos retroanalisados dos oito segmentos.

Tabela 11: Módulos retroanalisados dos segmentos do anel viário da UFJF.

\begin{tabular}{|c|c|c|c|c|c|}
\hline \multirow{2}{*}{ Segmento } & \multicolumn{5}{|c|}{ Módulos Retroanalisados (MPa) } \\
\hline & Revestimento & Base & Sub-Base & Reforço & Subleito \\
\hline 1 & 4.733 & 375 & 516 & 383 & 278 \\
\hline 2 & 3.929 & 310 & 274 & 298 & 231 \\
\hline 3 & 7.451 & 587 & 727 & 564 & 343 \\
\hline 4 & 3.407 & 419 & 314 & 190 & 201 \\
\hline 5 & 3.805 & 457 & 682 & 433 & 321 \\
\hline 6 & 3.522 & 355 & 299 & 263 & 244 \\
\hline 7 & 4.301 & 508 & 543 & 336 & 231 \\
\hline 8 & 4.619 & 300 & 211 & 180 & 177 \\
\hline
\end{tabular}

A etapa final foi a utilização dos dados de campo e retroanalisados juntamente com os dados de ensaio das misturas produzidas com RCD para o dimensionamento da camada de reforço. Utilizou-se o programa MeDiNa (do mesmo pacote do software BackMeDiNa), onde se entra com os dados referentes ao pavimento antigo, da camada nova de reforço e do tráfego. Os dados dos módulos retroanalisados foram importados diretamente do programa BackMeDiNa, sendo os demais dados inseridos pelo usuário manualmente.

Foram então dimensionadas as possíveis camada de reforço para as quatro misturas asfálticas. Para o projeto de camada de reforço, o programa MeDiNa considera apenas a percentagem de área trincada ao fim do período de projeto como delimitante da espessura do reforço. A Tabela 12 resume os valores de espessura da camada de reforço para os segmentos e entre parênteses a percentagem de área trincada no período de projeto (10 anos).

Tabela 12: Resultados obtidos no dimensionamento do reforço para as quatro misturas asfálticas.

\begin{tabular}{|c|c|c|c|c|}
\hline \multirow{2}{*}{ Segmento } & \multicolumn{4}{|l|}{ Mistura } \\
\hline & 1 & 2 & 3 & 4 \\
\hline 1 & $5 \mathrm{~cm}(27,0 \%)$ & $15 \mathrm{~cm}(64,5 \%)$ & $15 \mathrm{~cm}(40,2 \%)$ & $5 \mathrm{~cm}(25,7 \%)$ \\
\hline 2 & $5 \mathrm{~cm}(29,6 \%)$ & $15 \mathrm{~cm}(71,3 \%)$ & $15 \mathrm{~cm}(47,0 \%)$ & $5 \mathrm{~cm}(26,6 \%)$ \\
\hline 3 & $5 \mathrm{~cm}(24,0 \%)$ & $15 \mathrm{~cm}(56,4 \%)$ & $15 \mathrm{~cm}(32,8 \%)$ & $5 \mathrm{~cm}(24,5 \%)$ \\
\hline 4 & $5 \mathrm{~cm}(30,3 \%)$ & $15 \mathrm{~cm}(73,3 \%)$ & $15 \mathrm{~cm}(49,2 \%)$ & $5 \mathrm{~cm}(26,8 \%)$ \\
\hline 5 & $5 \mathrm{~cm}(27,3 \%)$ & $15 \mathrm{~cm}(63,1 \%)$ & $15 \mathrm{~cm}(38,6 \%)$ & $5 \mathrm{~cm}(25,9 \%)$ \\
\hline 6 & $5 \mathrm{~cm}(30,0 \%)$ & $15 \mathrm{~cm}(71,7 \%)$ & $15 \mathrm{~cm}(47,3 \%)$ & $5 \mathrm{~cm}(26,8 \%)$ \\
\hline 7 & $5 \mathrm{~cm}(27,2 \%)$ & $15 \mathrm{~cm}(64,8 \%)$ & $15 \mathrm{~cm}(40,6 \%)$ & $5 \mathrm{~cm}(25,8 \%)$ \\
\hline 8 & $5 \mathrm{~cm}(29,7 \%)$ & $15 \mathrm{~cm}(74,3 \%)$ & $15 \mathrm{~cm}(50,7 \%)$ & $5 \mathrm{~cm}(26,5 \%)$ \\
\hline
\end{tabular}

\section{DISCUSSÃO}

Os resultados dos ensaios de massa específica se mostraram um pouco inferiores quando comparados com agregados naturais. Segundo Leite (2001) é consenso que agregados reciclados apresentem valores um pouco menores que os apresentados por agregados virgens. Na comparação com outras pesquisas que se utilizaram de RCD, Gómez (2011) encontrou valores próximos. Para o valor de absorção, 
que é considerado o maior diferencial entre os agregados reciclados e naturais, os materiais da pesquisa apresentaram valores superiores ao de valores convencionais. Entretanto, quando contrastados com valores de pesquisas que se utilizaram de RCDs (LEITE, 2001; SILVA, 2009), os resultados se mostraram próximos. Em relação aos ensaios de abrasão, índice de forma e durabilidade, os valores encontrados para os materiais reciclados atenderam a norma para agregados em misturas de pré-misturados à frio (DNIT, 2010b).

$\mathrm{Na}$ montagem dos esqueletos minerais, a granulometria das misturas para as duas faixas se diferenciaram consideravelmente. As misturas que atenderam a Faixa C do DNIT 153/2010 apresentaram significativamente menor quantidade de finos do que a mistura produzida por Santana (1993). A maior quantidade de finos na segunda mistura pode gerar alguns problemas, uma vez que a absorção da parte fina é maior do que do restante dos materiais, podendo ocasionar maior quantidade de ligante asfáltica e uma mistura mais seca.

Em relação a dosagem Marshall, os valores encontrados para porcentagem de ligante das quatro misturas atenderam os requisitos de volume de vazios, estabilidade e fluência estipulados pela norma do DNIT 153-2010. Para teores menores (8-12\%), as duas primeiras misturas apresentaram valores diferentes, com resultados superiores de ligante da mistura 2, o que era de se esperar, uma vez que possui maior quantidade finos. Posteriormente, para maiores quantidades de teores de ligante (11-15\%), as misturas 3 e 4 apresentaram a mesma quantidade de teor de projeto (11\%). Comparados com misturas a quente, os teores de projeto foram, significativamente, superiores, uma vez que para misturas CBUQ os teores variam de 4-6\% (valores residuais). Ressalta-se aqui que para utilização das misturas à quente é utilizado teor de asfalto, enquanto que as misturas a frio são analisadas o teor de emulsão. Valores de referências foram difíceis, pois não se encontrou na literatura estudos com PMF com usos de RCD, entretanto, por experiência, o valor de $10 \%$ de teor de emulsão em PMF, o que representaria um teor residual de asfalto de $6 \%$ é constado como normal.

Para os ensaios mecânicos, os valores de resistência à tração e módulo de resiliência das misturas se mostraram inferiores a outros encontrados na literatura, como nas pesquisas de Silva (2009), Quiñones (2014) e Silva et al. (2016). Estes valores podem ser justificados pelo tipo de mistura (PMF em relação à CBUQ, para os dois primeiros trabalhos) e os tipos de agregados (reciclados em relação aos naturais, para a terceira pesquisa). Nota-se também diferença entre as misturas com diferentes faixas, uma vez que as misturas mais finas resultaram em RT e MR inferiores às misturas mais grossas, possivelmente explicado pelo arranjo dos agregados, que altera o volume de vazios. Na comparação entre o teor de ligante, percebe-se valores maiores de RT para misturas menor quantidade de ligante e maiores valores de MR para misturas com menor teor.

Os resultados de resistência à fadiga das misturas não apresentaram uma tendência geral entre o tipo de faixa e a quantidade de ligante. Percebe-se que para a faixa de deformações estudadas, a Mistura 2 foi que a que apresentou pelo comportamento à fadiga o maior resultado de FAF entre as misturas, podendo ser explicado pela maior quantidade de finos e maior teor de ligante. Já a Mistura 4 foi a que apresentou menor resistência a fadiga entre todas as misturas. Quiñenes (2014) concluiu em seu trabalho que misturas que se utilizaram de RCD apresentaram resistência ao trincamento por fadiga maior que em agregados 
convencionais, devido ao fato dos resíduos demonstrarem melhor entrosamento entre as partículas de maior cubicidade e também por apresentarem maior absorção, o que ocasiona misturas com maiores teores de ligante.

Em relação ao processo de retroanálise, nota-se valores superiores de rigidez para os segmentos 1, 3, 5 e 7 em relação aos demais. Observando os valores absolutos, consta-se que o revestimento asfáltico do pavimento flexível do anel viário da UFJF ainda possui um alto módulo elástico (chegando à ser maior que 7.000MPa em algumas bacias). Além disso, destacam-se os valores de módulos retroanalisados superiores das camadas subjacentes em relação às sobrejacentes.

Para a tentativa de uma possibilidade de dimensionamento da camada de reforço do anel viário utilizando da mistura de PMF e RCD, nota-se diferenças significativas entre as quatro misturas estudadas. As misturas 1 e 4 produziram estruturas com menores espessuras e áreas trincadas, sendo as que apresentaram melhor desempenho como camada de reforço. Tais resultados não foram notados na análise apenas laboratorial (ensaio de fadiga), uma vez que a mistura 4 apresentou pior desempenho no ensaio, mas na estrutura apresentou um bom comportamento. Já as misturas 2 e 3 apresentaram para todos os segmentos desempenho inferior ao estipulado pelo software, uma vez que a espessura limite é de $15 \mathrm{~cm}$ e a percentagem de área trincada máxima é de $30 \%$.

\section{CONCLUSÕES}

Altos valores de resíduos são gerados a partir de obras de construção e demolição e os materiais constituintes desses são altamente heterogêneos e variam conforme o tipo de edificação e o método empregado para sua obtenção. Além da atenção com o alto valor de resíduos gerado, há o fato da escassez de resíduos naturais e uma rápida deterioração das jazidas. A pesquisa em questão teve como objetivo caracterizar as propriedades dos resíduos de construção e demolição que quando reutilizados como agregados em camadas de reforço podem apresentar características físicas e mecânicas satisfatórias quando comparados com misturas produzidas com agregados virgens.

Os materiais reciclados utilizados como agregados nas misturas asfálticas apresentaram valores dentro do permitido pelas normas nos ensaios de caracterização. Destaca-se o valor alto de absorção do resíduo quando comparados com agregados naturais, devendo-se ao fato de apresentar diferentes materiais em sua constituição (tijolos e concreto) que conduzem a maior absorção.

A dosagem Marshall das quatros misturas estudadas apresentaram teores de projeto entre 9 e $11 \%$ de emulsão asfáltica, sendo valores superiores aos teores de ligante de mistura à quente. Por se tratar de misturas à frio e com uso de agregados mais absorsivos, as primeiras dosagens com teores inferiores apresentaram dificuldade na mistura, sendo a umidificação do agregado antes da mistura um processo eficaz.

As características mecânicas e dinâmicas das misturas apresentaram valores inferiores quando comparados a outros trabalhos que se utilizaram de misturas a quente e agregados naturais. Destaca-se as relações entre as faixas utilizadas e os teores de ligantes com os valores de resistência à tração e módulo de resiliência. Maiores teores de ligante na mistura produziram mistura menos resistentes e mais rígidas, 
enquanto que misturas mais densas (Faixa C) produziram misturas com maior RT e MR. A vida de fadiga das misturas variaram entre si, não apresentando uma tendência geral. Em suma, a Mistura com a Faixa C e com $11 \%$ de ligante foi a que apresentou o melhor comportamento ao trincamento.

O dimensionamento das misturas asfálticas como camadas de reforço em pavimentos flexíveis mostrou que a mistura 1 e 4 podem ser utilizadas como camada asfáltica. Ambas as misturas sendo aplicadas ao pavimento existente do anel viário da UFJF produziriam estruturas resistente ao trincamento no decorrer do período de projeto. Desta forma, aplicando-se a Faixa C do DNIT com teor de 9\% ou a Faixa XII de Santana (1993) com teor de ligante de $11 \%$, os resíduos de construção e demolição utilizados nesta pesquisa em misturas à frio poderiam ser aplicados como camada de reforço-

Diante disso, fica nítido a aplicabilidade de resíduos de construção e demolição como agregados em misturas asfálticas e de misturas à frio como alternativas as misturas convencionais em projetos de reabilitação de pavimentos. Espera-se então, futuras pesquisas com mais aplicações de tais metodologias como camadas asfálticas, uma vez que tais processos tendem a ser mais econômicos e ecológicos.

Ressalta-se aqui, que a pesquisa teve como objetivo analisar a possibilidade uma possível construção da camada de reforço com utilização de pré misturado a frio. Entretanto, o dimensionamento e posteriormente a execução da camada de reforço foi realizado com mistura à quente. $O$ enfoque foi mostrar um estudo de viabilidade na tentativa de possível reutilização de RCD com PMF.

\section{REFERÊNCIAS}

AASHTO. American Association of State and Transportation Officials. AASHTO Guide for Design of Pavement Structures. Washington: AASHTO, 1993.

ABRELPE. Associação Brasileira de Empresas de Limpeza Pública e Resíduos Especiais. 2018/2019 Panorama dos resíduos sólidos no Brasil. 2018.

ARULRAJAH, A.; PIRATHEEPAN, J.; DISFANI, M. M.; BO, M. W.. Geotechnical and geoenvironmental properties of recycled construction and demolition materials in pavement subbase applications. Journal of Materials in Civil Engineering, v.25, n.8, p.1077-1088, 2014. DOI: https://doi.org/10.1061/(ASCE)MT.1943-5533.0000652

ABNT. Associação Brasileira de Normas Técnicas. NBR 15116: Agregados reciclados de resíduos sólidos da construção civil: Utilização em pavimentação e preparo de concreto sem função estrutural - Requisitos. Rio de Janeiro: ABNT, 2004.

BALBO, J. T.. Pavimentação asfáltica: materiais, projeto e restauração. Oficina de Textos, 2007.

BERNUCCI, L. B.; MOTTA, L. M.; CERATI, J. A. P.; SOARES, J. B.. Pavimentação asfáltica: formação básica para engenheiros. Rio de Janeiro: Petrobrás, 2006.

CONAMA. Conselho Nacional do Meio Ambiente. Resolução № 307, de 5 de julho de 2002. Ministério das Cidades, Secretaria Nacional de Habitação. Brasília: DOU, 2002.
DEL REY, I.; AYUSO, J.; GALVÍN, A. P.; JIMÉNEZ, J. R.; BARBUDO, A.. Feasibility of using unbound mixed recycled aggregates from CDW over expansive clay subgrade in unpaved rural roads. Materials, v.9, n.11, p.931, 2016. Dol: https://doi.org/10.3390/ma9110931

DNER. Departamento Nacional de Estradas de Rodagem. Mistura betuminosa a frio, com emulsão asfáltica: ensaio Marshall. Método de Ensaio, 107/94. Rio de Janeiro: 1994a.

DNER. Departamento Nacional de Estradas de Rodagem. Pavimentação Flexíveis: Misturas betuminosas: Determinação da resistência à tração por compressão diametral - ME, 138/94. Rio de Janeiro, 1994b.

DNIT. Departamento Nacional de Infraestrutura e Transportes. Pavimentação asfáltica: Pré-misturado a frio com emulsão catiônica convencional. Especificação de serviço, 153/2010. Rio de Janeiro: DNIT, 2010a.

DNIT. Departamento Nacional de Infraestrutura e Transportes. Pavimentação: Solos: Determinação do módulo de resiliência: Método de ensaio, 134/2010. Rio de Janeiro: DNIT, 2010b.

DNIT. Departamento Nacional de Infraestrutura e Transportes. Pavimentação asfáltica: Ensaio de fadiga por compressão diametral à tensão controlada: Método de Ensaio 183/2010. Rio de Janeiro: DNIT, 2018.

DNIT. Departamento Nacional de Infraestrutura e Transportes. Manual de restauração de pavimentos asfálticos. IPR. Brasília: DNIT, 2006. 
DNIT. Departamento Nacional de Infraestrutura e Transportes. Sistema de Custos Rodoviários do DNIT SICRO. Rio de Janeiro: DNIT, 2015.

ESPARZA, L. A.; OSSA, A.; BOTERO, E.. Evaluation of the complex dynamic modulus of asphaltic concretes manufactured with construction and demolition waste (CDW) aggregates. Environmental Science and Pollution Research, v.27, p.11575-11586, 2020. DOI: https://doi.org/10.1007/s11356-020-07727-2

EUROSTAT. European Commission, Eurostat Statistics for Waste Flow Generation. EUROSTAT, 2017.

FERNANDES, C. G.. Caracterização macanística de agregados reciclados de resíduos de construção e demolição dos municípios do Rio de Janeiro e de Belo Horizonte para uso em pavimentação. Tese (Doutorado em Engenharia Civil) Universidade Federal do Rio de Janeiro, Rio de Janeiro, 2004.

FRANCO, F. A. C. P.. Método de dimensionamento mecanístico-empírico de pavimentos asfálticos-SISPAV. Tese (Doutorado em Engenharia Civil) - Universidade Federal do Rio de Janeiro, Rio de Janeiro, 2007.

GEDIK, A.. A review on the evaluation of the potential utilization of construction and demolition waste in hot mix asphalt pavements. Resources, Conservation and Recycling, v.161, p.104956, 2020. DOI: https://doi.org/10.1016/j.resconrec.2020.104956

GÓMEZ, A. M. J.. Estudo experimental de um resíduo de construção e demolição (RCD) para utilização em pavimentação. Dissertação (Mestrado em Geotecnia) Universidade de Brasília, Brasília, 2011.

HOU, Y.; JI, X.; SU, X.; ZHANG, W.; LIU, L.. Laboratory investigations of activated recycled concrete aggregate for asphalt treated base. Construction and Building Materials, v.65, p.535-542, 2014. DOI:

https://doi.org/10.1016/i.conbuildmat.2014.04.115

HUANG, Y.; BIRD, R. N.; HEIDRICH, O.. A review of the use of recycled solid waste materials in asphalt pavements. Resources, Conservation and Recycling, v.52, n.1, p.57-73, 2007 DOI: https://doi.org/10.1016/j.resconrec.2007.02.002

KAREEM, A. I.; NIKRAZ, H.; ASADI, H.. Evaluation of the double coated recycled concrete aggregates for hot mix asphalt. Constr. Build. Mater, v.172, p.544-552, 2018. DOI: https://doi.org/10.1016/j.conbuildmat.2018.03.158

KUMAR, R.. Influence of recycled coarse aggregate derived from construction and demolition waste (CDW) on abrasion resistance of pavement concrete. Construction and Building Materials, v.142, p.248-255, 2017. DOI:

https://doi.org/10.1016/j.conbuildmat.2017.03.077

LEITE, F. C.. Comportamento mecânico de agregado reciclado de resíduo sólido da construção civil em camadas de base e sub-base de pavimentos. Tese (Doutorado em Engenharia Civil) - Universidade de São Paulo, São Paulo, 2001.

LEVY, S. M.. Reciclagem do entulho da construção civil, para utilização com agregados para argamassa e concretos.
Dissertação (Mestrado em Construção Civil) - Universidade de São Paulo, São Paulo, 1997.

MACHADO, T. F. O.. Projeto de reforço para o pavimento flexível do anel viário da UFJF baseado no novo método de dimensionamento mecanístico empírico nacional. Dissertação (Mestrado) - Universidade Federal de Juiz de Fora, Juiz de Fora, 2019.

MEDINA, J.; MOTTA, L. M. G.. Mecânica dos Pavimentos. 3 ed. Rio de Janeiro: Inter ciência, 2015.

MELLO, L. G. R.; FARIAS, M. M.; PREUSSLER, E. S.; PREUSSLER, R.. Análise do impacto do período de projeto de pavimentos no custo global de obras rodoviárias. Revista Transportes, v.24, n.4, p.64-74, 2016. DOI: https://doi.org/10.14295/transportes.v24i4.1056

MENEGAKI, M.; DAMIGOS, D.. A review on current situation and challenges of construction and demolition waste management. Current Opinion in Green and Sustainable Chemistry, v.13, p.8-15, 2018. DOI: https://doi.org/10.1016/j.cogsc.2018.02.010

MILLS-BEALE, J.; YOU, Z.. The mechanical properties of asphalt mixtures with recycled concrete aggregates. Construction and Building Materials, v.24, n.3, p.230-235, 2010. DOI:

https://doi.org/10.1016/i.conbuildmat.2009.08.046

OSSA, A.; GARCÍA, J. L.; BOTERO, E.. Use of recycled construction and demolition waste (CDW) aggregates: A sustainable alternative for the pavement construction industry. Journal of Cleaner Production, v.135, p.379-386, 2016. DOI: https://doi.org/10.1016/j.jclepro.2016.06.088

PARANAVITHANA, S.; MOHAJERANI, A.. Effects of recycled concrete aggregates on properties of asphalt concrete. Resources, Conservation, Recycling, v.48, n.1, p.1-12, 2006 DOI: https://doi.org/10.1016/j.resconrec.2005.12.009

PASANDIN, A. R.; PEREZ, I.. Mechanical properties of hot-mix asphalt made with recycled concrete aggregates coated with bitumen emulsion. Construction and Building Materials, v.55, p.350-358, 2014. DOI: https://doi.org/10.1016/j.conbuildmat.2014.01.053.

PASANDIN, A. R.; PEREZ, I.. Laboratory evaluation of hot-mix asphalt containing construction and demolition waste. Construction and Building Materials, v.43, p.497-505, 2013. DOI: http://dx.doi.org/10.1016/j.conbuildmat.2013.02.052

QUIÑONES, F. S.. Aplicabilidade de resíduos reciclados da construção e demolição como agregados em misturas asfálticas. Dissertação (Mestrado em Geotecnia) Universidade do Brasília, Brasília, 2014.

REZENDE, L. R.; MARQUES, M. O.; OLIVEIRA, J. J.; CARVALHO, J. C.; GUIMARAES, R. C.; RESPLANDES, H. M. S.; COSTA, L. C. S.. Field Investigation of mechanic properties of recycled CDW for asphalt pavement layers. Journal of Materials in Civil Engineering, v.28, n.3, p.05015003, 2015. DOI: https://doi.org/10.1061/(ASCE)MT.1943-5533.0001420

SANTANA, H.. Manual de pré-misturados a frio. Rio de Janeiro: IBP, 1993. 
SILVA, C. A. R.. Estudo do agregado reciclado de construção civil em misturas betuminosas para vias urbanas.

Dissertação (Mestrado em Engenharia Civil) - Universidade Federal de Ouro Preto, Ouro Preto, 2009.

SILVA, T. K. D.; CARVALHO, C. A. B. D.; MARQUES, G. L. D. O.; SANT'ANNA, G. L.; SILVA, T. O. D.; MACHADO, C. C.. Dosagem de Misturas Betuminosas a frio e seu estudo sob efeitos de cargas estáticas e repetidas. Revista Árvore, v.40, n.1, p.97106, 2016.

SOUZA JÚNIOR, J. G. D.. Aplicação do novo método de dimensionamento de pavimentos asfálticos a trechos de uma rodovia federal. Dissertação (Mestrado em Engenharia Civil) - Universidade Federal do Rio de Janeiro, Rio de Janeiro, 2018.
USEPA. United States Environmental Protection Agency. Advancing sustainable materials management: $2017 \mathrm{fact}$ sheet: Assessing trends in material generation, recycling and disposal in the United States. USEPA, 2018.

VERISK MAPLECROFT. Waste Generation and Recycling Indices 2019: Overview and findings. VERISK MAPLECROFT, 2019.

ZOU, G.; ZHANG, J.; LIU, X.; LIN, Y.; YU, H.. Design and performance of emulsified asphalt mixtures containing construction and demolition waste. Construction and Building Materials, v.239, p.117846, 2019. DOI: https://doi.org/10.1016/i.conbuildmat.2019.117846 